\title{
Winter is coming
}

\author{
Cold temperatures put financial strain on millions of households for whom sufficient heating is \\ prohibitively expensive.
}

A cross the Northern Hemisphere, days are getting shorter and colder. For millions of households, the approach of winter is a source of anxiety about how they will afford to heat their homes. Heating in the winter is not simply a matter of comfort. Cold indoor temperatures have been strongly implicated in the phenomenon of excess winter mortality, in which more deaths occur in winter relative to summer months. Cold indoor temperatures are also associated with lesscatastrophic negative health effects, such as respiratory illness, particularly in young children ${ }^{1}$. Consequently, the World Health Organization recommends a minimum of $21^{\circ} \mathrm{C}$ in living rooms and $18{ }^{\circ} \mathrm{C}$ in all other rooms ${ }^{2}$. However, the costs of sufficiently heating a home in winter are not trivial, and are exacerbated by prolonged winters in some places, poor-quality housing stock, or, in the worst case, the combination of the two. Indeed, certain demographic groups, such as the elderly, people with chronic illness, and low-income households, spend a relatively greater proportion of their income on energy, leading to an uncomfortable choice: heat or eat.

Energy poverty refers to the inability to attain a socially and materially necessitated level of domestic energy services. In developed countries, where most households have stable access to energy, energy poverty is an issue of affordability (in this context the term 'fuel poverty' is often used, particularly in the UK). However, there is debate on how this should be quantified. In 2013, England moved from a $10 \%$ indicator, in which a household is considered fuel poor if they spend more than $10 \%$ of their income on energy expenditure, to a low income high costs (LIHC) indicator. According to LIHC, a household is fuel poor if they have necessary fuel costs above the national median average, and, were they to spend that amount, they would be left with residual income below the poverty line. This change was triggered by an influential review criticizing the $10 \%$ indicator for its emphasis on energy price and inability to properly identify those who might benefit from energy poverty alleviation programmes - the use of a ratio means that in principle relatively high-income households could be classified as energy poor, and very low-income households can have high energy costs to income ratios regardless of their required fuel spending ${ }^{3}$. According to the LIHC measure ${ }^{4}$, an estimated $11 \%$ of the population in England were fuel poor in 2015.

Critics of the LIHC measure ${ }^{5}$ note that it limits the definition of who is experiencing energy poverty. Indeed, fewer households are classified as fuel poor according to the LIHC measure compared to the $10 \%$ indicator $^{3,6}$. More specifically, high-cost households are by definition those in dwellings with poor energy efficiency. Consequently, government and policy is narrowly aimed at energy efficiency solutions. Home energy efficiency is undoubtedly an important contributing factor to energy poverty. For instance, northern countries such as Finland have long, cold winters, but they have better domestic insulation standards and thus lower rates of energy poverty and excess winter deaths than generally warmer countries such as Italy ${ }^{7,8}$. There is also evidence that energy efficiency interventions improve mental health, wellbeing, and quality of life in those designated as fuel poor?.

However, a focus on home energy efficiency alone neglects other drivers of energy poverty, such as failures in the energy market or the impact of austerity measures. It also implies that no assistance is needed for those in energy-efficient dwellings experiencing challenges such as unemployment, illness, or bereavement that can result in significant financial hardships ${ }^{5}$. At the Behavioral Science and Policy Association meeting this September, Macky McCleary, from the Rhode Island Department of Utilities and Carriers, noted that when people are unable to pay their utility bills, it's usually because they are facing other, more pressing financial challenges. The question he posed was how the utility provider could help consumers avoid the life-threatening consequences of having utilities turned off in the winter. Importantly, the people facing such risks are those unable to make even the minimum required bill payment, and so are unlikely to be helped by the simple bill reductions from energy efficiency improvements.

The LIHC indicator's focus on home energy efficiency also fails to account for other aspects of energy spending that can pose a significant financial burden. For instance, nearly $80 \%$ of working Canadians commute by private motor vehicle. When taking gasoline expenditures into account, the percentage of Canadians classified as energy poor (using a $10 \%$ indicator) more than doubles, from $9.4 \%$ for household electricity and natural gas costs only, to $19.4 \%$ (ref. ${ }^{10}$ ).

The difficulty in creating a single, successful indicator of energy poverty reflects its highly geographically variable and multi-dimensional nature. In fact, similar conversations are occurring around whether conceptual definitions of energy poverty capture the full scope of what it means to be energy poor, and whether distinguishing energy versus fuel poverty (which typically reflects an access versus affordability distinction) is useful for understanding how restricted energy consumption impacts wellbeing ${ }^{11,12}$. Indeed, energy use behaviour is tied to unique, personal, lived experiences that may not be easily quantified, as discussed in a News \& Views in this issue. For example, it is not clear that any expenditure-based indicator would capture the kind of energy poverty experienced by young adults living in transient rental housing and multiple-occupancy living arrangements documented in recent work ${ }^{13}$. Metrics and indicators are useful policy tools, but they must be treated with caution and selected on the basis of locally meaningful considerations, as different measures prioritize different facets of energy poverty, and represent particular vulnerabilities, losses of wellbeing, and potential injustices ${ }^{6}$.

Published online: 8 December 2017 https://doi.org/10.1038/s41560-017-0065-0

References

1. Liddel, C. \& Morris, C. Energy Policy 38, 2987-2997 (2010).

2. Housing, Energy and Thermal Comfort (World Health Organization, Copenhagen, 2007).

3. Hills, J. Fuel Poverty: The Problem and its Measurement (Centre for Analysis of Social Exclusion, 2011).

4. Annual Fuel Poverty Statistics Report, 2017 (2015 Data) (Department for Business, Energy and Industrial Strategy, 2017). 5. Middlemiss, L. Critical Soc. Policy 37, 425-443 (2017).

6. Robinson, C., Bouzarovski, S. \& Lindley, S. Energy Res. Soc. Sci. http://doi.org/cgh5 (2017).

7. Barnett, A. G. et al. J. Epidemiol. Community Health 59, 551-557 (2005).

8. Healy, J. D. Housing, Fuel Poverty and Health: A Pan-European Analysis (Ashgate Publishing Limited, 2004)

9. Grey, C. N. B., Schmieder-Gaite, T., Jiang, S., Nascimento, C. \& Poortinga, W. Indoor Built Environ. 26, 902-913 (2017).

10. Green, K. P., Jackson, T. Herzog, I. \& Palacios M. Energy Costs and Canadian Households: How Much are we Spending? (Fraser Institute, 2016).

11. Day, R., Walker, G. \& Simcock, N. Energy Policy 93, 255-264 (2016). 12. Bouzarovski, S. \& Petrova, S. Energy Res. Soc. Sci. 10, 31-40 (2015). 13. Petrova, S. Trans. Inst. British Geogr. http://doi.org/cdbx (2017). 